\title{
Organic Rankine cycle - review and research directions in engine applications
}

\author{
Angad Panesar ${ }^{1, *}$ \\ ${ }^{1}$ School of Computing, Engineering and Mathematics, University of Brighton, BN2 4GJ, UK
}

\begin{abstract}
Waste heat to power conversion using Organic Rankine Cycles $(\mathrm{ORC})$ is expected to play an important role in $\mathrm{CO}_{2}$ reductions from diesel engines. Firstly, a review of automotive ORCs is presented focusing on the pure working fluids, thermal architectures and expanders. The discussion includes, but is not limited to: R245fa, ethanol and water as fluids; series, parallel and cascade as architectures; dry saturated, superheated and supercritical as expansion conditions; and scroll, radial turbine and piston as expansion machines. Secondly, research direction in versatile expander and holistic architecture $\left(\mathrm{NO}_{\mathrm{x}}+\mathrm{CO}_{2}\right)$ are proposed. Benefits of using the proposed unconventional approaches are quantified using Ricardo Wave and Aspen HYSYS for diesel engine and ORC modelling. Results indicate that, the implementation of versatile piston expander tolerant to two-phase and using cyclopentane can potentially increase the highway drive cycle power by $8 \%$. Furthermore, holistic architecture offering complete utilisation of charge air and exhaust recirculation heat increased the performance noticeably to $5 \%$ of engine power at the design point condition.
\end{abstract}

\section{Introduction}

Diesel engines are projected to remain one of the primary power source in trucking, marine and rail sectors, hence, future engine developments will emphasise on $\mathrm{CO}_{2}$ reductions, alongside regulated emissions standards (e.g. Euro 6). Theoretical studies have shown indirect methods to be the more efficient technique for waste heat to power conversion for exhaust gases [1]. Organic Rankine Cycles (ORC) is stated as the preferred system when comparing the overall conversion efficiency and technology readiness level for highway trucking [2]. Exhaust gas recirculation (EGR) and post-turbine exhaust are being targeted due to higher quality and/or quantity. However, coolant and Charge Air Cooler (CAC) heat require innovative approaches (e.g. direct engine block heat recovery) [3].

ORC demonstrations of multiple heat recovery in series, parallel and cascade arrangements are taking advantage of the broader choice of working fluids and advancements in expanders. For relatively low, medium and high temperature heat sources, R245fa by Domingues et al. [4], ethanol by Larsen et al. [5] and MM by Fernandez et al. [6] has been suggested. Additionally, with emphasis on environment, R1234yf was indicated optimal from a thermo-economic approach by Yang et al. [7]. Experimental

${ }^{*}$ Corresponding author: a.s.panesar@brighton.ac.uk 
results with efficiencies approaching $80 \%$ with scroll expander by Wang et al. [8], 70\% with screw expander by Zhang et al. [9] and 65\% with piston expander by Seher et al. [10] have been presented. Furthermore, the trucking sector is integrating prototypes to address issues relating to durability, packaging and controls [11]. ORCs were the most demonstrated technology in the $5-15 \mathrm{~kW}$ range, offering thermal efficiencies around $8-12 \%$ and a potential of $4-6 \%$ reduction in fuel consumption. Specific system weight and cost following standardisation are projected to be $10 \mathrm{~kg} / \mathrm{kW}$ and $300 £ / \mathrm{kW} \mathrm{[12-14].}$

This paper consists of two parts. Firstly, a conceptual and technical review of automotive ORCs is presented focusing on the pure working fluids, thermal architectures, expanders and application specific challenges. The review is divided by the common classifications of working fluids. Consideration is given to the associated expander inlet conditions (illustrated using Fig. 1) and heat recovery arrangements (illustrated using Fig. 2). Secondly, research direction in versatile expander and holistic architecture $\left(\mathrm{NO}_{\mathrm{x}}+\mathrm{CO}_{2}\right)$ are proposed to partially address the challenges hindering ORC implementation. This extends the earlier works which linked process requirements to the fundamental fluid properties and process integration guidelines to optimised energy conversion [3]. Engine and ORC modelling was performed in Ricardo Wave and Aspen HYSYS (using Peng-Robinson equation of state) $[15,16]$. The relative simulation results, against the published ORC conclusions, quantified the benefits of using methods less common within the automotive sector and unconventional approaches.

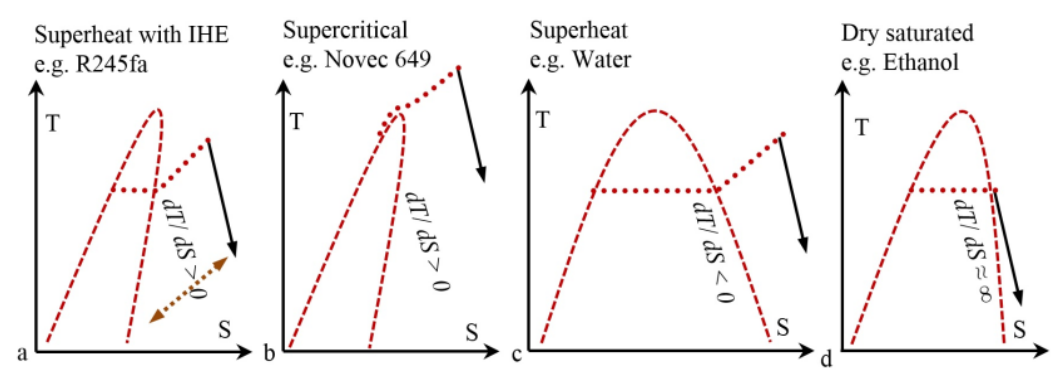

Fig. 1. Illustrative literature ORC operation (a) Recuperated (b) Supercritical (c) Superheated (d) Dry vapour.

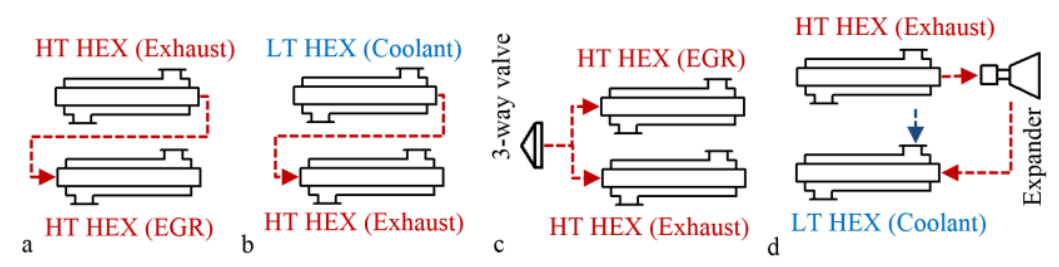

Fig. 2. Illustrative literature heat recovery architecture (a, b) Series (c) Parallel (d) Cascade.

\subsection{Review - refrigerants}

Using nearly dry saturated vapour expansion (Fig. 1d), Wang et al. simulated a cascade architecture (Fig. 2d), where the interconnected High Temperature (HT) cycle and Low Temperature (LT) cycles recovered exhaust heat using R245fa and coolant heat using R134a [17]. Despite a low 7\% ORC thermal efficiency due to the LT coolant, a 3\% point increase in gasoline engine thermal efficiency was calculated. Cascade architectures 
allowed higher heat exploitation, however, the challenges relating to system size, control and complexity may be prohibitive for automotive applications. Hussain and Brigham also simulated coolant and exhaust heat using R245fa, however, in a series architecture (Fig. 2b) [18]. The residual exhaust heat coming out of the evaporator was also used for preheating. The power generated during city drive cycle could only provide $1 / 3^{\text {rd }}$ of the accessory load requirement due to the on-off conditions of the considered hybrid gasoline engine.

Cummins demonstrated EGR and exhaust parallel architecture (Fig. 2c), initially using a superheated recuperated R245fa cycle (Fig. 1a). In the continued work, the ORC system was packaged on a truck employing low rates of EGR and high efficiency Selective Catalytic Reduction (SCR) system [11]. The system delivered 4.5-6\% fuel efficiency improvements, the turbine output power was mechanical to the crankshaft through a gearbox and the condenser was a direct air cooled condenser at the front of the engine cooling module. R245fa has a high Global Warming Potential (GWP) of 1030. This coupled with the lack of non-flammable alternatives has led to intense development efforts by the chemical companies to design improved molecular makeup refrigerants [19]. Cogswell et al. has examined a $5 \mathrm{~kW}$ supercritical recuperated ORC using Novec 649, a $4^{\text {th }}$ generation low GWP refrigerant (Fig. 1b) [12]. Furthermore, Cummins have replaced 245fa with R1233zd(e) [11].

In summary, for refrigerant as the working fluid, the majority of publications have selected R245fa, a drying fluid due to higher molecular complexity. R245fa played a key role in the initial resurgence of automotive ORC due to a positive stationary ORC experience and the possibility to modify existing sector hardware. R245fa was better suited for heat recovery $<300^{\circ} \mathrm{C}$ and condensing temperatures $<50^{\circ} \mathrm{C}$.

Finally, scroll expanders, screw expanders and radial turbines, all have been demonstrated using refrigerants. For scroll expanders under $10 \mathrm{~kW}$ output, Barccoa et al. have shown efficiencies up to $70 \%$ with Pressure Ratio (PR) of 5.5:1 and maximum cycle temperature of $190^{\circ} \mathrm{C}$ [20]. With improvements in rotor profile of screw expanders, Leibowitz et al. presented efficiencies up to $70 \%$ at engine RPMs for under $25 \mathrm{~kW}$ output [21]. Subcritical turbine envelope with maximum inlet conditions, pressure ratio and maximum speed of $27 \mathrm{bar}, 230^{\circ} \mathrm{C}, 10.8: 1$ and 70,000 rpm was demonstrated by Halliwell [22]. Furthermore, supercritical radial inflow turbine with 15 primary and splitter vanes was modelled by Cogswell et al. [12]. Inlet conditions, peak efficiency, pressure ratio, power output and speed was 28 bar, $260^{\circ} \mathrm{C}, 80 \%, 12: 1,10 \mathrm{~kW}$ and 78,000 rpm.

\subsection{Review - inorganics}

Using water as the working fluid, Katsanos et al. simulated exhaust only and series exhaust then EGR architectures (Fig. 2a) for a truck engine, offering average fuel consumption improvements of $4.3 \%$ and $6.8 \%$ [23]. The majority of the heat needed for evaporation came from exhaust and the superheating was covered by the high EGR rate (Fig. 1c) at the mid-speed mid-load engine condition (B50). Cooper et al. additionally showed a low sensitivity to engine speed and load [13]. At high EGR rate and high-speed high-load engine condition, Arunachalam et al. theoretically evaluated Rankine cycle architectures, even combining CAC [24]. They showed that the power produced from EGR only heat recovery was $72 \%$ of the cycle which recovered all the three gaseous sources.

Simulations investigating the controllability of the Rankine cycle for exhaust only architecture in highway drive cycle with practical operating pressures was presented by Weerasinghe et al [14]. The higher fuel consumption improvements reported were due to a steam storage reservoir between the evaporator and the expander, providing an energy buffer through periods of varying engine operation. With HT heat favoring water and LT heat favoring $4^{\text {th }}$ generation refrigerants (e.g. R1234yf), the combination of these two 
different classes of fluids were also proposed in water-organic cascade architecture by Bae et al. [25]. Additional inorganic cycles in literature included, supercritical $\mathrm{CO}_{2}$, ammonia and Kalina cycle, however, due to the requirement of a low condensing temperature, excessive system pressures for equal performance to refrigerants and complex packaging, respectively, these may be inappropriate options for truck applications [26, 27].

In summary, Rankine cycle was stated to be effective only for HT heat (e.g. series exhaust then EGR architecture) usually $>400^{\circ} \mathrm{C}$ and paired with condensing temperature $>100^{\circ} \mathrm{C}$. Water gave the highest thermal efficiency for a given $\Delta \mathrm{T}$ of source, however, required expander PR was higher for a given evaporator and condenser temperature compared to refrigerants [3]. Screw expanders were also modelled for two-phase water expansion in the HT cascade section offering noticeable improvements [28, 29].

\subsection{Review - hydrocarbons}

AVL initially performed fluid comparisons study between R245fa and ethanol, highlighting a favorable case for ethanol. In the continued work, they demonstrated a superheated ethanol cycle with IHE for trucks using exhaust only architecture due to low EGR rates [30]. For fixed evaporation $\left(120^{\circ} \mathrm{C}\right)$ and condensation $\left(70^{\circ} \mathrm{C}\right)$ temperatures, average fuel consumption improvement of $3.8 \%$ was shown. Seher et al. compared working fluids at a condensation temperature of $100^{\circ} \mathrm{C}$ using a piston expander and turbine in the EGR and exhaust parallel architecture [10]. Ethanol was considered as a suitable fluid as it provided high performance using either piston expander or turbine. Edwards et al. investigated EGR only, exhaust only and EGR and exhaust parallel architectures using ethanol [31]. The controlled use of EGR and exhaust showed the greatest simulated fuel consumption improvement of $4.3 \%$. The ORC condenser was integrated with the HT engine radiator and all architectures utilised the same piston expander map.

For series coolant and exhaust architecture, compared to refrigerants, contrary conclusions can be drawn for hydrocarbons from the simulations of Vaja and Gambarotta [32]. Thermodynamic attributes using benzene showed that the series coolant and exhaust architecture gave an improvement only $1 / 10^{\text {th }}$ higher than exhaust only architecture. Hence, the marginal drop in efficiency for a reduction in cost and complexity favoured the simpler architecture.

In summary, ethanol in EGR and exhaust parallel architectures was the preferred hydrocarbon at $300-400^{\circ} \mathrm{C}$ heat (i.e. typical exhaust gas temperatures). Hydrocarbons generally decompose quickly, thus reducing their overall toxicity risk, they also have GWP $<20$ [19]. Hydrocarbons do present the challenge of flammability, however, improved technologies to reduce risk and use in the context of a closed system has led to a revived interest. For exhaust only architecture, alkanes have also been recommended due to excellent thermo-physical and environmental characteristics by Shu et al. [33]. In high $\Delta \mathrm{T}$ applications, studies demonstrated efficient piston expanders with engine RPMs and high inlet temperature/pressure $\left(380^{\circ} \mathrm{C} / 32\right.$ bar $)$ as suitable alternative to turbines for water and ethanol [10].

\subsection{Research direction - vapour and two-phase expanders}

In this section, the fundamental results for two-phase expansion are presented and compared against superheated expansion. Furthermore, included in the discussion are the challenges and recommendations for two-phase expansion. Heat recovery was considered from a turbocharged, 12.8 L truck engine model (Euro 6 with high efficiency SCR) at the low-speed mid-load condition (A50). The ORC inputs, assumptions and sizes presented in Table 1, which correspond to realistic values, were utilised. Simulations were conducted 
using cyclopentane, the proposed fluid in this study, and ethanol, a common literature fluid. Heat transfer areas (approximated as $U A$, product of the heat transfer coefficient and area) and expander size (approximated as PR) were fixed. Expansion and pumping efficiencies were kept constant at relatively lower values (55\%).

Table 1. Boundary conditions, assumptions and sizes considered during modelling.

\begin{tabular}{|c|c|c|c|c|c|c|c|}
\hline \multicolumn{2}{|c|}{$\begin{array}{l}\text { Common in all } \\
\text { simulations }\end{array}$} & \multicolumn{2}{|c|}{$\begin{array}{c}\text { Specific to A50 } \\
1160 \mathrm{rpm}, 131 \mathrm{~kW}\end{array}$} & \multicolumn{2}{|c|}{$\begin{array}{c}\text { Specific to B50 } \\
1440 \mathrm{rpm}, 158 \mathrm{~kW}\end{array}$} & \multicolumn{2}{|c|}{ Specific to B50 } \\
\hline Parameters & Values & Parameters & Values & Parameters & Values & Parameters & Values \\
\hline$T_{\text {cool air in }}$ & $30^{\circ} \mathrm{C}$ & $T_{e x h}$ & $380^{\circ} \mathrm{C}$ & $T_{\text {exh }}$ & $375^{\circ} \mathrm{C}$ & $U A_{\text {exh HEX }}$ & $1000 \mathrm{~W} /{ }^{\circ} \mathrm{C}$ \\
\hline$T_{\text {cool air out }}$ & $50^{\circ} \mathrm{C}$ & $m_{e x h}$ & $0.176 \mathrm{~kg} / \mathrm{s}$ & $m_{\text {exh }}$ & $0.223 \mathrm{~kg} / \mathrm{s}$ & $U A_{C A C+E G R}$ & $1680 \mathrm{~W} /{ }^{\circ} \mathrm{C}$ \\
\hline$\eta_{\text {pump }}$ & $55 \%$ & $c_{p \text { exh }}$ & $1.14 \mathrm{~kJ} / \mathrm{kg}^{\circ} \mathrm{C}$ & $T_{C A C}$ & $90^{\circ} \mathrm{C}$ & $U A_{\text {cond }}$ & $2000 \mathrm{~W} /{ }^{\circ} \mathrm{C}$ \\
\hline$\eta_{\exp }$ & $55 \%$ & $U A_{\text {exh } H E X}$ & $600 \mathrm{~W} /{ }^{\circ} \mathrm{C}$ & $m_{C A C}$ & $0.223 \mathrm{~kg} / \mathrm{s}$ & $P R_{\exp }$ & $16: 1$ \\
\hline & & $U A_{\text {cond }}$ & $1100 \mathrm{~W} /{ }^{\circ} \mathrm{C}$ & $T_{E G R}$ & $430^{\circ} \mathrm{C}$ & $T_{\text {cond }}$ & $50^{\circ} \mathrm{C}$ \\
\hline & & $V F R_{\exp } X=1$ & 19:1 & $m_{E G R}$ & $0.033 \mathrm{~kg} / \mathrm{s}$ & $\triangle P_{H E X}$ fluid & 0.6 bar \\
\hline & & & & $\eta_{\text {trans }}$ & $94 \%$ & $\Delta P_{\text {cond fluid }}$ & 0.2 bar \\
\hline
\end{tabular}

Fig. 3a presents the expansion Volume Flow Ratio (VFR), net power and thermal efficiency results for cyclopentane and ethanol with expansion inlet condition of liquid $(X=0)$ to dry saturated vapour $(X=1)$ expansion. With reduction in vapour fraction, the thermal efficiency decreased (11 to $8.7 \%$ ), due to the reduction in the expansion enthalpy change. Nonetheless, the reduction in the net power of cyclopentane was limited to below $15 \%$ ( 4.7 vs. $5.6 \mathrm{~kW})$ when a vapour fraction $\geq 0.4$ was maintained. For approximately $1 / 6^{\text {th }}$ of the duration in highway drive cycle, power is not generated due to the insufficient temperature and pressure conditions at the conventional expander inlet. Hence, a working fluid and expander combination, which can tolerate two-phase expansion then potentially offers a partial means to recover more frequent power.

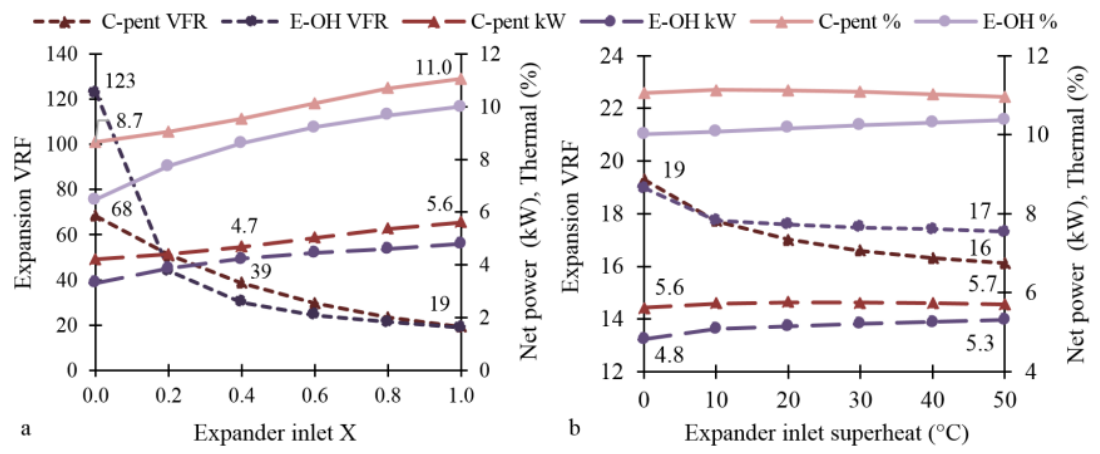

Fig. 3. Simulation results for (a) Two-phase expansion (b) Superheated expansion.

The two-phase expansion was compared against the conventional approach of superheated expansion. Fig. $3 \mathrm{~b}$ presents the results for cyclopentane and ethanol of dry saturated vapour to $50^{\circ} \mathrm{C}$ superheated expansion. At the dry saturated vapour condition, cyclopentane offered $15 \%$ additional net power $(5.6 \mathrm{vs}$. $4.8 \mathrm{~kW}$ ) for equal $U A$ and VFR values to ethanol. With increasing superheat, the net power results converged ( $\Delta 15$ to $\Delta 7 \%$ ) due to the opposing shape of the T-S curve for the two fluids. As a result, for organic fluids in high $\Delta \mathrm{T}$ applications, the design point corresponded close to the dry saturated vapour condition. 
The VFR with cyclopentane for the two-phase expansion $(X=0.4)$ was noticeably higher (2 times) than the dry saturated vapour expansion (39:1 vs 19:1). This may not necessarily correspond to the requirement of a linear increase in the design point VFR. This can be attributed to the density of the two-phase being much higher (3.7 times) compared to the dry saturated vapour. As a result, operational VFR of the two-phase expansion is expected to be greater than the design point VFR of the dry saturated vapour expansion. Cyclopentane offered an equal VFR to ethanol at $X=1$ with lower PR (16:1 vs. 19:1) and a relatively lower VFR variation between $X=0-1$ (3.6 vs. 6.5 times), providing a more practical solution.

The fluid side of the exhaust heat exchanger (HEX) typically includes two temperature measurements, one at the inlet $\left(T_{i n}\right)$ and the other at the exit $\left(T_{\text {out }}\right)$. With the two-phase expansion, the HEX only requires an additional in-build intermediate temperature measurement $\left(T_{\text {inter }}\right)$. When $T_{\text {inter }} \approx T_{\text {out }}$, it can be assumed the HEX exit is in a two-phase state (i.e. $X>0.4$ ). Due to the limited impact on net power and VFR for $X>0.4$, the above approach is expected to suffice, limiting the challenge relating to the ORC control.

The two-phase $(X=0.4)$ expansion process is expected to be slightly inefficient when compared to the dry saturated vapour expansion. If the two-phase expansion efficiency was assumed to be $50 \%$, the net power generated was still $75 \%$ of the design point. This indicates that despite the decreasing net power by reducing vapour fraction, power can be produced more frequently in a transient drive cycle using expanders that can expand two-phase as well as vapour. Finally, assuming power generation potential for $2 / 3^{\text {rd }}$ of the untapped transient highway drive cycle, the implementation of expander tolerant to two-phase increased the drive cycle power by $8 \%$.

\subsection{Research direction - holistic $\mathrm{NO}_{x}$ and $\mathrm{CO}_{2}$ reducing thermal architectures}

Modern emission compliant truck engines with high efficiency SCR systems offer three gaseous sources for potential heat recovery. CAC for cooler intake temperatures and engine downsizing, EGR for $\mathrm{NO}_{\mathrm{x}}$ reduction, and post-turbine exhaust gases. As such, emission standards and $\mathrm{CO}_{2}$ reduction cannot be uncoupled and has to be addressed on the same engine platform, since techniques for $\mathrm{NO}_{\mathrm{x}}$ reduction have a high impact on engine thermal efficiency and the available waste heat. There is a potential challenge in integrating exhaust gases with $\mathrm{CAC}$, due to lower quality $\left(75-150^{\circ} \mathrm{C}\right)$ and transient flows (boost pressures $1.5-3$ bar $)$, and EGR, due to lower quantity $(\approx 15 \%$ of exhaust $)$ and higher quality $\left(50-100^{\circ} \mathrm{C}>\right.$ exhaust). In this section, holistic revision of the engine and ORC thermal architecture is presented with the objective of proposing an integrated heat recovery, engine downsizing and $\mathrm{NO}_{\mathrm{x}}$ limiting platform. Simulations were conducted using cyclopentane at B50, an operating condition which corresponds closely to the expected ORC design point in highway trucking.

Since CAC and EGR thermal conditions differ amongst the engine applications, Fig. 4a presents an ORC utilising a combined medium temperature HEX. This is used for cooling the blended charge air and exhaust recirculation, and is located post-compressor in the engine platform as shown in Fig. $4 \mathrm{~b}$ (SCR excluded for illustration). Due to the available cooling margin in the engine cooling module, the LT engine radiator was modified into the ORC condenser and the air temperature rise was limited to $20^{\circ} \mathrm{C}$. Compared to the exhaust $\operatorname{HEX}\left(U A=1000 \mathrm{~W} /{ }^{\circ} \mathrm{C}\right)$, the combined $\operatorname{HEX}\left(U A=1680 \mathrm{~W} /{ }^{\circ} \mathrm{C}\right)$ was larger in size due to a cooling requirement to $60^{\circ} \mathrm{C}$ and relatively medium quality heat. Nonetheless, the larger size can be partially compensated since these streams are already a part of the engine cooling module. Additionally, this architecture reduces the number of thermal components, offers suitable medium quality heat for series heat recovery, and utilises only higher quality exhaust heat. 


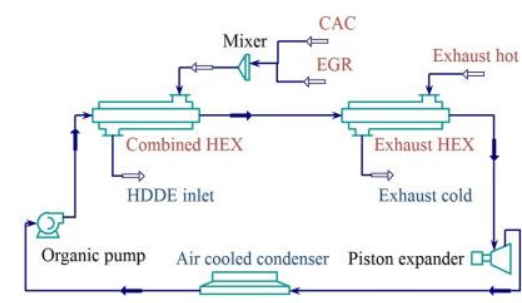

a

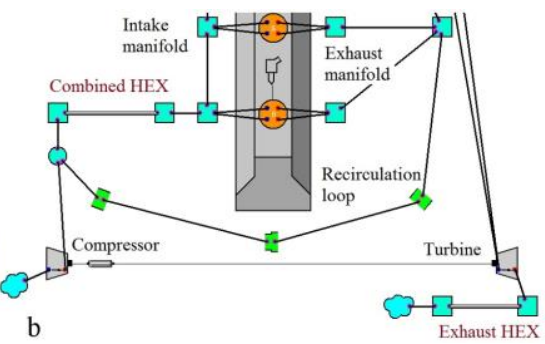

Fig. 4. (a) Holistic architecture modelled in Aspen HYSYS (b) Modified truck engine modelled in Ricardo Wave.

In the simulated case, heat recovery was 20.2 and $57.9 \mathrm{~kW}$ in the combined and the exhaust HEX, resulting in the complete utilisation of CAC and EGR heat (Table 1). The minimum temperature difference was 10 and $20^{\circ} \mathrm{C}$ for combined and the exhaust HEX. Such minimum temperature difference values offer a suitable trade-off between the heat transfer area and the ORC power [3]. The maximum and minimum cycle temperature/pressure combination were $180^{\circ} \mathrm{C} / 20.5$ bar and $50^{\circ} \mathrm{C} / 1$ bar during vapour expansion condition. The ORC system was $10.1 \%$ efficient and generated a net power of $7.9 \mathrm{~kW}$, which corresponded to $5 \%$ of engine power. These results were compared against ethanol for exhaust heat recovery architecture only, a total improvement of $36 \%(\Delta 2.1 \mathrm{~kW})$ was recorded.

\section{Conclusion}

Despite an increased risk, ORCs have demonstrated higher overall conversion efficiency and technology readiness level for $\mathrm{CO}_{2}$ reductions in highway trucking. The $8-12 \%$ thermally efficient systems for $5-15 \mathrm{~kW}$ output have shown $4-6 \%$ reduction in fuel consumption. The specific system weight and cost following standardisation are projected to be $10 \mathrm{~kg} / \mathrm{kW}$ and $300 £ / \mathrm{kW}$. Firstly discussed was, the use of exhaust, EGR and coolant as heat sources; R245fa, ethanol and water as working fluids; series, parallel and cascade as thermal architectures; dry saturated, superheated and supercritical as expansion inlet conditions; and scroll, radial turbine and piston as expansion machines. Furthermore, emerging ORC approaches included: use of $4^{\text {th }}$ generation refrigerants, innovative methods for LT heat recovery, and two-phase water expansion in HT cascade section. Secondly, research direction in versatile expander and holistic architecture $\left(\mathrm{NO}_{\mathrm{x}}+\mathrm{CO}_{2}\right)$ were proposed. By linking process requirements to the fundamental fluid properties and process integration guidelines to optimised energy conversion, ORC modelling in Aspen HYSYS and engine modelling in Ricardo Wave was conducted. Results indicated that, the implementation of versatile piston expander tolerant to two-phase and using cyclopentane can potentially increase the highway drive cycle power by $8 \%$. Implementation challenges relating to: high expansion VFR, two-phase ORC control and expansion inefficiency were also considered. Finally, holistic revision of the engine and ORC thermal architecture was presented with the objective of proposing an integrated heat recovery, engine downsizing and $\mathrm{NO}_{\mathrm{x}}$ limiting platform. This reduced the number of thermal components, offered suitable medium quality heat for series architecture, resulted in complete utilisation of charge air and recirculation heat, utilised only high quality exhaust heat and increased the ORC performance to $5 \%$ of engine power at the design point.

\section{References}

1. Z. Xu, J. Liu, J. Fu, C. Ren, SAE Int. 10.4271/2013-01-1648 (2013) 
2. C. Sprouse, C. Depcik, Appl. Therm. Eng. 51, 711-722 (2013)

3. A. Panesar, Doctoral thesis, 10.13140/RG.2.1.4559.0248 (2015)

4. A. Domingues, H. Santos, M. Costa, Energy 49, 71-85 (2013)

5. U. Larsen, L. Pierobon, F. Haglind, C. Gabrielii, Energy 55, 803-812 (2013)

6. F.J. Fernández, M.M. Prieto, I. Suárez, Energy 36, 5239-5249 (2011)

7. M.H. Yang, R.H. Yeh, Applied Energy 149, 1-12 (2015)

8. H. Wang, R. Peterson, K. Harada, E. Miller, Energy 36, 447-458 (2011)

9. Y.Q. Zhang, Y.T. Wu, G.D. Xia, C.F. Ma, Energy 77, 499-508 (2014)

10. D. Seher, T. Lengenfelder, J. Gerhardt, N. Eisenmenger, Aachen Colloquium, October 8-12, Aachen, Germany (2012)

11. D.W. Stanton, SAE Int. J. Engines 6, 1395-1480 (2013)

12. F.J. Cogswell, D.W. Gerlach, T.C. Wagner, J. Mulugeta, IMECE, November 11-17, Denver, USA (2011)

13. C. Cooper, F. Kamakate, T. Reinhart, M. Kromer, Reducing Heavy-Duty Long Haul Combination Truck Fuel Consumption and $\mathrm{CO}_{2}$ Emissions (2009)

14. R. Weerasinghe, R. Stobart, S. Hounsham, App. Therm. Eng. 30, 2253-2256 (2010)

15. Ricardo Software, WAVE version 8.1 (2015)

16. Aspen Technology Software, HYSYS version 8 (2015)

17. E.H. Wang, H.G. Zhang, Y. Zhao, B.Y. Fan, Energy 43, 385-395 (2012)

18. Q.E. Hussain, D.R. Brigham, IDETC/CIE, August 15-18, Montreal, Canada (2010)

19. J.M. Calm, G.C. Hourahan, ICR, August 21-26, Prague, Czech Republic (2011)

20. R. Braccoa, S. Clementeb, D. Michelib, M. Reini, ECOS, June 26-29, Perugia, Italy (2012)

21. H. Leibowitz, N. Stosic, I.K. Smith, ASME IMECE, November 5-10, Chicago, USA (2006)

22. Halliwell, International Conference on Turbochargers and Turbocharging, May 15-16, London, UK (2012)

23. C. Katsanos, D. Hountalas, T. Zannis, E. Yfantis, SAE Int. 10.4271/2010-01-0315 (2010)

24. P.N. Arunachalam, M. Shen, M. Tuner, P. Tunestal, SAE Int. 10.4271/2012-01-1602 (2012)

25. S. Bae, H. Heo, J. Park, H.Y. Lee, SAE Int. 10.4271/2013-01-0046 (2013)

26. H. Tian, G.Q. Shu, H. Wei, X. Liang, SAE Int. J. Engines 6, 766-776 (2013)

27. M. He, X. Zhang, K. Zeng, K. Gao, Energy 36, 6821-6829 (2011)

28. I.K. Smith, N. Stosic, E. Mujic, A. Kovacevic, Journal of Process Mechanical Engineering 225, 117-125 (2011)

29. J. Song, C.W. Gu, Applied Energy 156, 280-289 (2015)

30. H. Teng, J. Klaver, T. Park, G. Hunter, SAE Tech. 10.4271/2011-01-0311 (2011)

31. S. Edwards, J. Eitel, E. Pantow, P. Geskes, Int. J. Commer. Veh. 5, 395-406 (2012)

32. I. Vaja, A. Gambarotta, Energy 35, 1084-1093 (2010)

33. G. Shu, X. Li, H. Tian, X. Liang, Applied Energy 119, 204-217 (2014) 